\title{
Tendências da Literatura Brasileira Contemporânea
}

A última revolução na prosa artística brasileira data de 1946 (Sagarana); exatamente dez anos mais tarde, surgiria, com os manifestos e o "plano-piloto" dos concretistas, a última revolução na poesia. Isso propōe desde logo as perspectivas em que devemos estudar as tendências da literatura contemporânea no Brasil: trata-se, por um lado, de uma literatura que ainda luta com o monstruoso cadáver do Modernismo, atravessado na estrada, e, por outro lado, de uma literatura que procura elaborar em criação propriamente dita novas concepções estéticas, as quais, no que se refere à poesia, ainda não passaram realmente dos domínios puramente teóricos. A prosa, ao contrário, não tem teoria, ou a teoria está sendo estruturada "a posteriori", o que é excelente, a partir da obra de Guimarães Rosa; quanto a este último, se, com a sua própria extraordinária e impetuosa originalidade, fechou automaticamente todos os caminhos de uma eventual "escola" literária, forneceu, com Grande Sertão: Veredas (1956), a prova de que era possível inventar um romance ao mesmo tempo extremamente literário e lingüistico, a meio caminho entre Joyce e Mário de Andrade - pois não é somente no Ulysses, para não falar de Finnegans Wake, mas também em Macunaima, que se encontram reunidos aqueles dois caracteres, a contribuição propriamente nacional comparecendo sob a forma clássica de regionalismo.

E' curioso, mas perfeitamente compreensível, que sejam os críticos mais próximos da poesia concreta (e alguns outros que, embora heréticos, manifestam os mesmos gostos de crítica filológica) os primeiros analistas a mergulhar com alguma profundidade na obra de Guimarães Rosa, procurando fixar-lhe os pontos de referência essenciais. Com isso, está sendo negligenciado até hoje o seu caráter, se não mais importante, pelo menos tão significativo quanto o da invenção linguística, que é o da sua renovação romanesca: uma leitura atenta, para além do anteparo das palavras, demonstra que Grande Sertão: Veredas é um romance de extraordinária estrutura, construído com mão de mestre, evocando fundos problemas espirituais, situado intelectualmente na encruzilhada das 
grandes correntes da fiç̧ão, desde a Idade Média aos nossos dias, e tendo criado, no plano das figuras humanas, um tipo literário, que é, como se sabe, a ambição suprema e a finalidade mesma de toda a prosa de ficção. $O$ romance de Guimarães Rosa, sendo igualmente original e inventivo na língua, no estilo, no conteúdo e na configuração dos personagens, não está longe, portanto, do que se poderia denominar a obra total, quaisquer que sejam, ao nivel do pormenor, as reservas que se lhe possam opor. Se muitos críticos parecem exceder-se nos louvores e na idéia de que os livros de Guimarães Rosa estabelecem rumos definitivos e invariáveis para a literatura brasileira do futuro, não se lhes pode negar o mérito de insistir sobre o alcance da primeira obra verdadeiramente revolucionária a surgir na prosa artística brasileira depois do Modernismo.

Com efeito, os outros grandes romancistas brasileiros contemporâneos parecem situar-se mais numa espécie de classicismo pós-modernista do que propriamente nas linhas ebulientes da vanguarda literária: os "dois grandes" dos anos 30, Erico Veríssimo e Jorge Amado, escreveram, respectivamente, com O Tempo e o Vento (1949) e com Gabriela, Cravo e Canela (1958), qualquer coisa como uma síntese épica dos seus livros anteriores; ou, se quisermos, estes últimos não passaram de inconsciente preparação para os dois grandes romances, nos quais, afinal, encontraram a sua própria identidade literária. Diga-se desde logo que, justamente por serem menos originais, nas perspectivas totalizadoras acima apontadas, os romances de Erico Veríssimo e Jorge Amado serão muito mais "universalizáveis" que o de Guimarães Rosa: a versão norte-americana deste ultimo (The Devil To Pay. in the Backlands [New York, 1963, reimpresso em 1971]) demonstrou, como seria de esperar, que é possível traduzir-lhe a "língua", mas não a "linguagem", e, muito menos, o estilo: para encontrar correspondências em língua inglesa para o texto brasileiro teria sido preciso um James Joyce; para traduzi-lo em francês, um outro Romain Rolland (o Romain Rolland de Colas Breugnon). Grânde Sertão: Veredas, no texto inglês, os contos de Corpo de Baile em francês, dão a idéia de um Ulysses escrito por Erskine Caldwell, de um Gargantua escrito por Jean Giono; o próprio Jorge Amado que, no prefácio da tradução americana, não esconde o seu orgulho por ter sido um dos primeiros a "foresee the rapid universalization of his [Guimarães Rosa ] work", acrescenta imediatamente: "Not so much or even because of its formal aspect, more limited to our national frontiers, as because of the world revealed, re-created, and given enduring life through the extraordinarily achieved beings, through the Brazil that breathes in its every page".

Há, pois, um aspecto formalista que seria o traço fundamental de toda a literatura brasileira contemporânea e que, antes de qualquer outro, the marcaria as tendências atuais: podemos, mesmo, dizer que a linha do formalismo é a invisível fronteira que separa os escritores contemporâneos dos que já são, ou começam a ser, "históricos", tanto na ficção e na poesia quanto na crítica e no ensaio: embora a crítica literária no Brasil tenha sido, 
nestes últimos anos, mais abstrusa do que realmente criadora de idéias teóricas e estéticas, mais afetada do que interpretativa, mais repleta de doutrinas do que rica em proposições iluminantes ou enriquecedoras, sempre é certo que, ela também, tem posto toda a ênfase nos aspectos formais da obra de arte, na sua natureza de criação lingúística.

Nessas perspectivas, poderíamos apontar o romancista José Geraldo Vieira como o grande injustiçado da fiç̧ão brasileira. Ele também, muito antes de Guimarães Rosa, fez do romance uma "máquina" literária e linguística: contudo, pode-se imaginar que o caráter convencional da sua língua, que não inventa um dicionário mas apenas explora as possibilidades dos dicionários existentes, fá-lo passar, aos olhos dos "novos críticos" e dos críticos novos, como uma espécie de ancestral ou de romancista à margem das correntes características do nosso tempo. Tal situação de marginal acompanha em todos os momentos a carreira de José Geraldo Vieira; mas, se houver na literatura brasileira, como em qualquer outra, um lugar de honra para os escritores que vêem o romance mais como um produto das belas-letras do que como um reflexo realista da vida comum, então é certo que o autor de Terreno Baldio (1961)e de AQuadragésima Porta (1948) tem a sua presença assegurada na história literária do país. Não deixa de ser picante acentuar que é um pouco nessa direção que se encaminhou o Jorge Amado de Os Velhos Marinheiros (1961) a Teresa Batista Cansada de Guerra (1972): isso prova que o Modernismo, a partir, digamos, de 1945, está bem morto, e que os sobreviventes da grande época, diante da impossibilidade de prolongá-lo, tentaram criar-lhe um "classicismo", o que foi bem sucedido entre os melhores. Clarice Lispector, que é alguma coisa como um José Geraldo Vieira menos rico em seiva romanesca e em imaginação, já sobrevive apenas como contista, depois do extraordinário sucesso literário de Perto do Coração Selvagem (1943); ora, como contista, ela seria alguma coisa como um Guimarães Rosa urbano, o Guimarães Rosa possível de uma classe média citadina, muito mais do que o Kafka que ela procurava sugerir com os romances posteriores a 1943 ou que o RobbeGrillet que procura emular nos seus livros mais recentes.

Ora, é justamente no romance urbano, e também nas linhas de uma renovação formal do gênero -- mas renovação técnica e estrutural, não lingüística ou estilística -- que se situa a última grande revelação do gênero no Brasil... o velho Marques Rebelo de Oscarina (1931) e de $A$ Estrela Sobe (1938). Com efeito, O Espelho Partido (1959) tem todo o caráter estranho e misterioso das grandes obras de arte: em certo sentido, pode-se dizer que a tentativa de Marques Rebelo ainda é mais ousada que a de Guimarães Rosa, pois depende menos de efeitos vistosos e sensíveis à primeira vista, repousa menos sobre o pitoresco, provoca mais a inteligência do que os sentidos, será mais cerebral do que emocional. Se, com Maria Alice Barroso e alguns jovens escritores publicados, geralmente, por editoras menores, o "novo romance" fez a sua entrada no Brasil, Marques Rebelo poderia ser visto como uma espécie de mestre mais idoso desse 
grupo; sem as inclinações "poéticas" de muitos dos romancistas ultimamente surgidos (que, infelizmente, caem com mais frequência na falsa poesia -- a "poesia" de que o primeiro Jorge Amado oferecia tantos exemplos -- do que se alçam à atmosfera rarefeita da prosa poética). Marques Rebelo restabelece, entretanto, o rumo propriamente romanesco, indicando que, na ficção, há um limite extremo que só se ultrapassa à custa da descaracterização da obra. E' a este perigo que se expôs a romancista de Perto do Coração Selvagem, e em que afinal sucumbiu nos livros posteriores; no conto, ao contrário, que tem uma sólida tradição poética (Tchecov, K. Mansfield...) e no qual a visão poética, por sua própria brevidade, encontra ambiente favorável, ela revela qualidades que não são muito diferentes, em natureza, das de Guimarães Rosa.

Contudo, as tendências formalistas da literatura contemporânea encontram uma reação bastante sensível entre os escritores que parecem voltar a um certo realismo pré-modernista. Por um momento pareceu que estava passando, para a prosa artística brasileira, a idade das grandes invenções e das grandes revoluções: Guimarães Rosa, que, na verdade, se sobreviveu um pouco a si mesmo, começava a sentir, na década de 60 , o peso dos vinte anos transcorridos desde a sua estréia, substituído, é verdade, no extenuante revesamento literário, por atletas de fôlego mais curto: Mário Donato, José Condé, Carlos Heitor Cony, Otto Lara Resende, todos eles mais afeiçoados ao tema do que à forma e contentando-se com o que poderíamos chamar, à falta de melhor têrmo, a prosa realista. Apenas Lygia Fagundes Telles manifesta, por intermitências, certos anseios poéticos: seria interessante verificar mais de perto, por exemplo, até que ponto o sucesso de Clarice Lispector repercutiu no seu tom de voz, nos seus "gestos" estilísticos.

Assim, por paradoxo, a prosa brasileira está vivendo um período simultâneo de formalismo e de realismo. Não mais o "realismo socialista" dos anos 30 (tão bem encarnado nos primeiros romances de Jorge Amado), mas o realismo puramente escolástico, de que José Lins do Rego, Graciliano Ramos, Rachel de Queiroz, foram, naquela década, os grandes praticantes. Voltaram à literatura de ficção os temas chamados "grosseiros", a observação minuciosa do mundo exterior, a visão pessimista do homem, a sátira social, a linguagem direta e simples, o interesse pelo comportamento, o desafio às convenções "burguesas" e a moda do enredo determinado, a intriga sólida e bem desenvolvida. Neste último aspecto, a ficção brasileira continua a sofrer da sua carência tradicional, pois que, a uma intriga geralmente "dramática", corresponde invariavelmente uma desoladora pobreza de ação. $O$ ficcionista brasileiro é capaz, em regra, de inventar o dado de base da sua história, mas já se mostra bem menos hábil ao desenvolvê-lo numa ação correspondente; daí a sensação de imobilidade que nos transmite a maior parte dos contos e romances, mesmo aqueles em que "acontecem" muitas coisas. E' que a situação romanesca permanece idêntica de começo a fim, o personagem raramente manifestando aquelas 
sutis transformações de personalidade (dentro de um quadro estável de psicologia) que revelam, justamente, a passagem do tempo. Este último valor é o grande ausente da fiç̧ão brasileira: é uma ficção newtoniana ou euclidiana, mais do que uma ficção bergsoniana ou einsteiniana. Isso indicaria o seu inegável anacronismo ou a sua "a-historicidade", se tomarmos o têrmo como designativo de insensibilidade ao clima espiritual da época: acrescento desde logo que será preciso alguma coisa mais do que simples experimentações técnicas (como as do "novo romance", por exemplo), para que a ficção mergulhe realmente na grande corrente impetuosa da história; trata-se, antes, de uma questão de psicologia e de sensibilidade espiritual.

Não se tratando aqui de um levantamento onomástico dos grandes e dos menos grandes escritores brasileiros contemporâneos, mas de um quadro das tendências mais características de nossa literatura atual, vista em seu conjunto, não teria cabimento a análise pormenorizada da obra de cada um, nem a menção de outros ficcionistas que, embora típicos em seus processos, não parecem influir na global fixação de rumos. Da mesma forma, deixarei um pouco na sombra o ensaio literário, tomada a palavra no sentido amplo: com exceção da crítica formalista, acima referida, o ensaio alcançou, também, um plano de classicismo de que não vejo como poderá sair sem perder muitas das suas qualidades: e, com relação à crítica formalista, penso, mesmo, que muitas das suas singularidades estruturais só se obtêm em detrimento das virtualidades ensaísticas: a análise formal, por sua própria natureza, perde em generalidade crítica o que possa ganhar em precisão analítica. Por isso mesmo, a crítica moderna está continuamente exposta ao perigo da atomização, abdicando, talvez com excessiva e imprudente ligeireza, da sua grande missão, que é a de constituir um "corpus" orgânico de idéias literárias. Não é menor o risco oposto, odas construções puramente teóricas e abstratas, para nada dizer dos críticos que se deixam fascinar pelas novidades doutrinárias como os selvagens pelo brilho das lantejoulas. O problema da crítica, para usar o título do livro em que Paul de Man estudou a "retórica da crítica contemporânea", está entre a cegueira e a perspicácia; e também, como ele mesmo escreve, entre as belas concepções do espírito e a crítica efetivamente praticada. Verifica-se em grande número de críticos uma "discrepância paradoxal entre as declarações gerais que fazem sobre a natureza da literatura (e sobre as quais fundam os seus respectivos métodos) e os resultados reais das suas interpretações. Suas descobertas sobre a estrutura dos textos contradizem a concepção global que tomaram como modelo. E não apenas deixam de perceber essa discrepância, como parecem alimentar-se dela, e ficam devendo a própria agudeza a pressupostos que essa agudeza condena". (Cf. Blindness \& Insight, New Y ork, 1971).

Pode-se marcar discrepância correspondente entre as teorias do Concretismo e o texto poético que delas resultou, o que, de resto, não deve surpreender, se pensarmos que elas eram, afinal de contas, mais uma teoria crítica sobre a literatura. Em 1957, o primeiro manifesto afirmava que "a 
poesia concreta assumia uma responsabilidade total perante a linguagem"; na prática, como se sabe, os poetas da escola fragmentaram a linguagem em palavras isoladas e jamais conseguiram restabelecer, a partir desses módulos, o tecido global de uma linguagem poética. Em 1958, o "Planopiloto para Poesia Concreta", acentuando "a importância da idéia do ideograma", definia-o como um "apelo à comunicação não-verbal", o que é a negação mesmo da linguagem. A Luta Corporal (1954), de Ferreira Gullar, foi um livro "revolucionário" que, em larga medida, marcava os limites possiveis do Concretismo: depois dele, embora a parte teórica do movimento haja fixado com maior ênfase os seus princípios, pouco se thes acrescentou em matéria propriamente "poemática".

A idéia de uma poesia "tipográfica", "figurativa" ou "charadística", mais do que "conteudística" e convencionalmente versificada, encontraria ancestrais ilustres e menos ilustres, mesmo no Brasil: os esforçados acadêmicos do século 17 já haviam dado com ela, legando-nos exemplos perfeitos como o "Labirinto cúbico" em homenagem ao Vice-rei D. Vasco Fernandes César de Meneses, construído sobre a expressão In utroque Cesar, e sobre a qual Anastácio Ayres de Penhafiel escreveu também un anagrama, gênero que se pode legitimamente encarar como o humilde antepassado da poesia concretista:

I - nvicto Vasco, César, sempre Augusto,

$\mathrm{N}$-ome é o vosso, que lido em toda a parte,

$\mathrm{V}$-ocifera, e convoca do DEUS Marte,

$\mathrm{T}$ - odo o peito que é forte, e é mais robusto:

$\mathrm{R}$ - égio pois; mas suspende, e não sem susto,

Ó-Musa o pletro, e a lira póe de parte,

Q- ue quem canta elogios com pouca arte,

$\mathrm{V}$-em a ser nos encômios sempre onusto.

E - sclarecido César, se os Romanos

C-om louvorao seu César não sucinto

E - sta letra aplicaram lá em seus anos;

S-abei, que com afeto não distinto,

A - vós aplicam hoje os Lusitanos

$\mathrm{R}$-eduzida de amor a um labirinto.

Gregório de Matos, de seu lado, não desdenhou esse tipo de experiências, deixando alguns poemas de estrutura "concretista" bem mais complexos, aliás, que os exemplares modernos. 
Labirinto cúbico

(Século XVII)

\begin{tabular}{|lllllllllllllll}
\hline$I$ & $N$ & $U$ & $T$ & $R$ & $O$ & $Q$ & $U$ & $E$ & $C$ & $E$ & $S$ & $A$ & $R$ \\
$N$ & $I$ & $N$ & $U$ & $T$ & $R$ & $O$ & $Q$ & $U$ & $E$ & $C$ & $E$ & $S$ & $A$ \\
$U$ & $N$ & $I$ & $N$ & $U$ & $T$ & $R$ & $O$ & $Q$ & $U$ & $E$ & $C$ & $E$ & $S$ \\
$T$ & $U$ & $N$ & $I$ & $N$ & $U$ & $T$ & $R$ & $O$ & $Q$ & $U$ & $E$ & $C$ & $E$ \\
$R$ & $T$ & $U$ & $N$ & $I$ & $N$ & $U$ & $T$ & $R$ & $O$ & $Q$ & $U$ & $E$ & $C$ \\
$O$ & $R$ & $T$ & $U$ & $N$ & $I$ & $N$ & $U$ & $T$ & $R$ & $O$ & $Q$ & $U$ & $E$ \\
$Q$ & $O$ & $R$ & $T$ & $U$ & $N$ & $I$ & $N$ & $U$ & $T$ & $R$ & $O$ & $Q$ & $U$ \\
$U$ & $Q$ & $O$ & $R$ & $T$ & $U$ & $N$ & $I$ & $N$ & $U$ & $T$ & $R$ & $O$ & $Q$ \\
$E$ & $U$ & $Q$ & $O$ & $R$ & $T$ & $U$ & $N$ & $I$ & $N$ & $U$ & $T$ & $R$ & $O$ \\
$C$ & $E$ & $U$ & $Q$ & $O$ & $R$ & $T$ & $U$ & $N$ & $I$ & $N$ & $U$ & $T$ & $R$ \\
$E$ & $C$ & $E$ & $U$ & $Q$ & $O$ & $R$ & $T$ & $U$ & $N$ & $I$ & $N$ & $U$ & $T$ \\
$S$ & $E$ & $C$ & $E$ & $U$ & $Q$ & $O$ & $R$ & $T$ & $U$ & $N$ & $I$ & $N$ & $U$ \\
$A$ & $S$ & $E$ & $C$ & $E$ & $U$ & $Q$ & $O$ & $R$ & $T$ & $U$ & $N$ & $I$ & $N$ \\
$R$ & $A$ & $S$ & $E$ & $C$ & $E$ & $U$ & $Q$ & $O$ & $R$ & $T$ & $U$ & $N$ & $I$ \\
\hline
\end{tabular}

\section{Soneto}

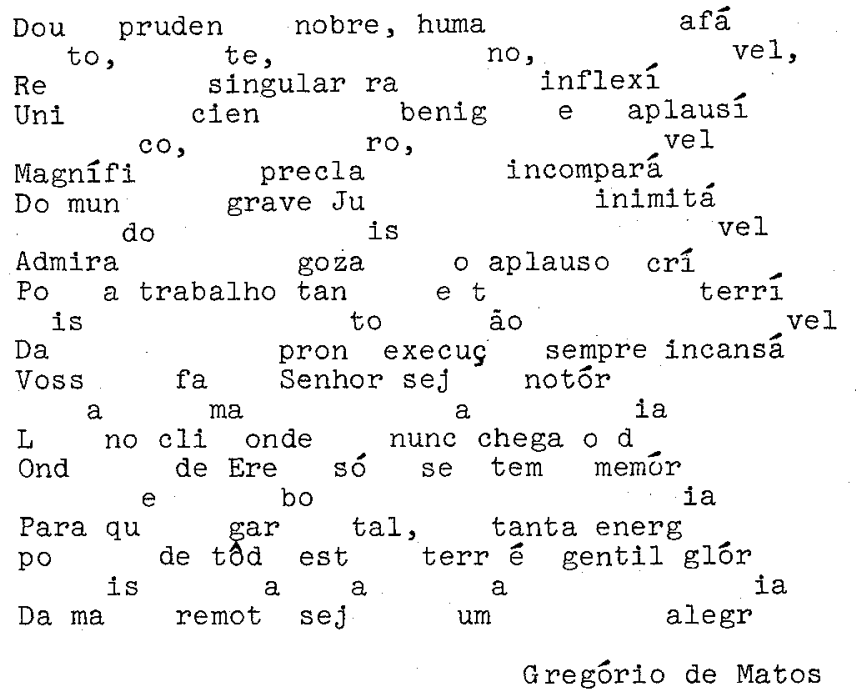


Os concretistas brasileiros reivindicam a sua precedência histórica e afirmam haver criado uma "poesia de exportação". E' preciso dizer que os meios internacionais ainda não reconheceram tal prioridade, registrando-se o aparecimento de poetas da mesma tendência na Suíça e na Suécia em 1953, na Austria em 1955, na Alemanha e no Japão em 1957, na França em 1962 , e em outros países. Os núcleos ${ }^{2}$ oncretistas em cada país, tanto quanto no Brasil, permaneceram claramente isolados e excêntricos, mas o "movimento", na década de 50, foi de caráter internacional. Nos Estados Unidos, as suas duas fontes principais foram e. e. cummings e Ezra Pound, mas, nas palavras de Mary Ellen Solt, "seria exagerado falar de um movimento de poesia concreta nos Estados Unidos". O livro de Ellen Solt, Concrete Poetry: A World View (Bloomington, Indiana, 1967) e a Encyclopedia of Poetry and Poetics, dirigida e publicada por Alex Preminger (Princeton, 1967) tendem a conferir a prioridade aos poetas suíços e, em particular, a Eugen Gomringer; contudo, Ellen Solt admite que o encontro de 1955, em Ulm, entre Décio Pignatari e Max Bill "pode ser tido como o início do movimento internacional de poesia concreta". De resto, tais questões de precedência individual não têm historicamente maior importância, desde que as Parole in libertà (1912), de Marinetti, e os Caligrammes (1918), de Apollinaire, devem ser vistos como os imediatos precursores modernos do Concretismo. Desde 1943, por exemplo, e para lembrar apenas um caso, o futurista italiano Carlo Belloli escrevia e publicava poemas "concretos".

A luta entre as vanguardas sendo, como é, interminável e feroz, o Concretismo, movimento típico da década de 50, já em 1961 se via contestado pelo "poema-praxis", invenção de Mário Chamie, exemplificada desde logo no volume Lavra Lavra. Como nas palavras famosas de Jean-Paul Sartre a respeito da revolução, a poesia-praxis encontra a própria legitimidade no ato de fazer-se; tanto quanto o Concretismo, a Praxis rejeita a noção de verso (livre ou regular), à espera do momento em que Cassiano Ricardo decretaria a eliminação do próprio vocábulo, substituindo-o, no dicionário poético, pelo nome de "linossigno".

Na verdade, a grande influência sobre os concretistas (que a admitem) como sobre os praxistas (que a silenciam) parece a do poeta João Cabral de Melo Neto, cujo volume Duas Aguas (1956) poderá vir a ser, futuramente, um dos marcos históricos da poesia moderna no Brasil. Cabral situa-se, originalmente, no ponto de interseç̧ão da poesia modernista com a poesia pós-modernista; digamos, mais precisamente, que ele parecia destinado a assegurar a sucessão de Carlos Drummond de Andrade, assim como este representou a evoluçầo da poesia propriamente modernista para a poética "consolidante" dos anos 30 e 40. João Cabral e Jorge de Lima (muito mais o primeiro que o segundo) seriam os dois nomes a guardar para uma análise hoje mais necessária do que nunca, que tentasse explicar a decidida tendência formalista que, em determinado momento, repudiou a inclinação social ou sociológica, se não puramente pitoresca e humorística, da década de 20. 
E' bem possível que, reveladas tais correntes profundas, as revoluções posteriores pareçam menos revolucionárias e, talvez, menos duradouras; da mesma forma, se considerarmos a fundo o que significa a evolução de João Cabral, será fácil surpreender na vanguarda um certo recuo tático e estratégico. A história contemporânea, mesmo a literária, não se escreve, vive-se; mas é já evidente que, na década de 70 , o "contemplador" da poesia-objeto se reconverteu no leitor da poesia propriamente dita.

Quanto ao leitor de romances, já terá igualmente percebido um fenômeno que até agora, segundo parece, tem escapado aos observadores da cena literária: o papel histórico de Guimarães Rosa, no que se refere às técnicas e à natureza da ficção, foi o de abrir caminhos, e não o de propor modelos. Os que o tomarem por modelo não poderão senão imitá-lo; os que o tomaram como exemplo, estão renovando a ficção brasileira. Contam-se nesse número escritores como António Callado e Ariano Suassuna. O primeiro, embora haja estreado em $1954 \mathrm{com}$ Assunção de Salviano, é somente em 1968 que assume, com Quarup, o lugar que era o seu entre os nossos romancistas mais eminentes; o segundo, escreveu, em 1959, com o Auto da Compadecida, o teatro correspondente ao novo clima intelectual aberto por Grande Sertão, mas é em 1971 que A Pedra do Reino o coloca, juntamente com António Callado e Mário Palmério, no plano ideal a que o livro de Guimarães Rosa havia elevado a ficção brasileira.

Os dois grandes romances políticos que são Quarup e A Pedra do Reino mostram que a obra de Guimarães Rosa, além de ter marcado época por sua inegável originalidade, foi igualmente fecunda na medida em que, revelando o que era possível fazer no romance, estimulou a originalidade alheia; é uma lição de dialética criadora, especialmente destinada aos que pensaram ingenuamente que o romance brasileiro, a partir de 1956, só poderia sobreviver se imitasse Grande Sertão -- o que seria, precisamente, a melhor maneira de torná-lo estéril.

Será certamente uma surpresa verificar que Mário Palmério pouco ou nada deve a Guimarães Rosa, nem mesmo no plano de exemplo acima referido: Vila dos Confins apareceu em 1956, isto é, no mesmo ano que Grande Sertão: Veredas. E' claro, mas talvez seja necessário dizê-lo, que Sagarana nada tem a fazer nestas perspectivas; a conclusão proposta pelos fatos é que Guimarães Rosa e Mário Palmério resultaram da mesma misteriosa conjuntura literária, o que é tanto mais evidente quanto se trata de obras estilisticamente diferentes (não me refiro apenas ao estilo de escrita, mas à estrutura do estilo narrativo). E', de novo, um romance político, e, com os dois anteriores, completa três espécies claramente distintas dessa forma romanesca. Completa? Se os estudos sobre a natureza do romance em Grande Sertão não estivessem tão atrasados, saberiamos já, a esta altura, que esse é também, em aspecto importante, um romance político -- exatamente nas coordenadas de política brasileira que Vila dos Confins iria estabelecer no mesmo ano. Essa obscura, mas impressionante, similaridade de atmosfera e de tom conduz muitos leitores a pensar que 
Mário Palmério estava imitando Guimarães Rosa, quando, na realidade, ambos trabalhavam simultaneamente sobre o mesmo material e acabaram por transmitir a mesma imagem (inclusive, é preciso dizê-lo, no que se refere à qualidade literária propriamente dita).

Acrescente-se que Mário Palmério foi além, no plano romanesco, com - Chapadão do Bugre, em 1965, enquanto Grande Sertão ficaria para sempre a única tentativa romanesca de Guimarães Rosa. Esses fatos sugerem alguma revisão no quadro de estimativas literárias atualmente em vigor; como sempre, o lugar-comum que passa por julgamento estético já começa a transformar em cegueira o que ato há pouco ainda era brilhante sagacidade.

New York University

WILSON MARTINS 